\title{
Characterization of hot-mix asphalt made with recycled concrete aggregates that have been cured for 4 hours in the oven
}

\author{
Ana Mª Rodríguez Pasandín ${ }^{1, a}$, Ignacio Pérez Pérez ${ }^{2, b}$ and Breixo Gómez \\ Meijide $^{3, c}$
}

\author{
${ }^{1}$ Universidade da Coruña, E. T. S. I. Caminos, Canales y Puertos, Campus de Elviña s/n, 15071. A \\ Coruña, Spain \\ ${ }^{2}$ Universidade da Coruña, E. T. S. I. Caminos, Canales y Puertos, Campus de Elviña s/n, 15071. A \\ Coruña, Spain \\ ${ }^{3}$ Universidade da Coruña, E. T. S. I. Caminos, Canales y Puertos, Campus de Elviña s/n, 15071. A \\ Coruña, Spain
}

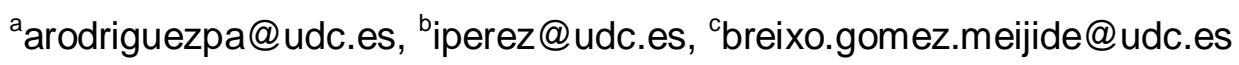

Keywords: recycled concrete aggregates, hot-mix asphalt, water resistance, stiffness, permanent deformation

\begin{abstract}
In this research a laboratory characterization of hot-mix asphalt (HMA) made with recycled concrete aggregates (RCA) from construction and demolition waste (CDW) as base layer in road construction has been conducted. HMA containing 5\%,10\%, 20\% and $30 \%$ of RCA in place of virgin aggregate were evaluated. To improve water resistance of the mixtures, they were left in an oven for 4 hours at mixing temperature before compaction to allow the bitumen absorption and, in addition, obstructing the mortar pores, strengthening the attached mortar onto the RCA surface and thus, preventing water pathways. The tested mixtures complied with Spanish water resistance requirement and also showed a water resistance performance much higher than that of the mixtures that were not cured in the oven. Stiffness and resistance to permanent deformation were also studied showing satisfactory results.
\end{abstract}

\section{Introduction}

Recycled concrete aggregates (RCA) from construction and demolition waste (CDW), have been widely used in construction as concrete or unbound pavement layers [1,2], because they have numerous environmental benefits [3] such as mitigating natural resource depletion or reducing visual effects derived from quarry extraction. Nevertheless, when RCA is used as a granular material the fines can dissolve in water, causing a $\mathrm{pH}$ increase in underground water, which may affect the surrounding vegetation [4]. In this way, it must be noticed that HMA is water impermeable, thus RCA is probably suitable for use in bituminous mixtures for pavements in road construction [4]. However, until now, only a small number of investigations on the use of this type of debris in HMA have been conducted [4-16].

The poor quality of RCA causes the engineering properties of HMA containing RCA to be different than those of conventional mixtures, i.e., those made with natural aggregates. Particularly, some researchers [12-16] have observed that HMA made with RCA was shown to have inadequate water resistance, which causes stripping that negatively affects the durability of the mixes. The authors stated that, as can be appreciated in figure 1, this effect is mainly due to the porous nature of the mortar attached onto RCA surface [12-16], which can absorb a great amount of water. In addition, the easy separation of the mortar attached under compression and crushing [12] could be responsible for this insufficient water resistance. 


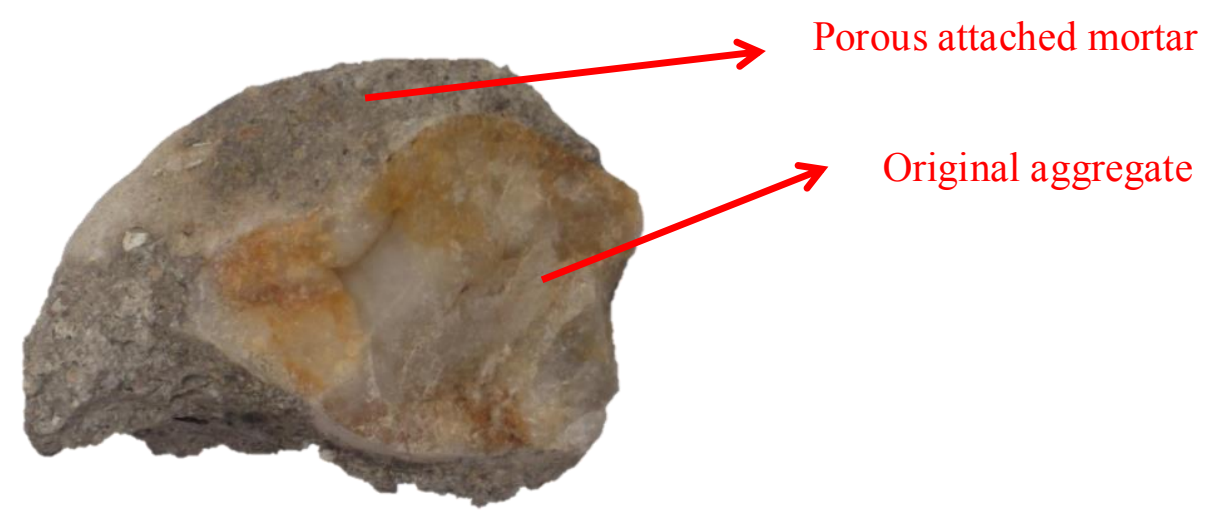

Figure 1: Recycled concrete aggregates used in this investigation.

Since moisture damage is one of the most important factors that contribute to the premature deterioration of flexible pavements [17], the aim of this investigation is to improve the water resistance of HMA made with RCA. In this way, HMA with percentages of $5 \%, 10 \%, 20 \%$ and $30 \%$ of RCA as coarse aggregate in place of natural aggregate were manufactured at optimum Marshall bitumen content. The loose mixtures were cured in an oven for 4 hours at mixing temperature before compaction. During the curing time the bitumen can be absorbed by the pores of the attached mortar, obstructing them and also strengthening the mortar and thus, preventing the water pathways. Stiffness and resistance to permanent deformation of such mixtures were also studied.

\section{Materials and methods}

Aggregates. In this investigation two types of aggregates were used: hornfels as natural aggregates and RCA. RCA were supplied by a CDW recycling plant in Madrid (Spain). As can be seen in figure 2 the RCA were mainly formed by petrous materials $(89.3 \%)$ such as concrete or aggregates. The rest of the constituents of RCA were bituminous materials (6.5\%), bricks (3.6\%) and impurities $(0.6 \%)$ such as gypsum, glass or wood.

Binder and filler. A B50/70 binder from Venezuela was used to manufacture the mixtures. Gray Portland cement type CEM II/B-M (V-L) $32.5 \mathrm{~N}$ ) was used as filler.

Marshall mix design. The Marshall mix design with 75 blows per face was used to manufacture the HMA cylindrical samples $(\phi 101.6 \mathrm{~mm} \times 63.5 \mathrm{~mm})$ and to determine the optimum bitumen content, following NLT-159/86 [18]. The mixing temperature was $170^{\circ} \mathrm{C}$ while the compaction temperature was $165^{\circ} \mathrm{C}$. As said before, the loose mixtures with $5 \%, 10 \%, 20 \%$ and $30 \%$ of RCA were cured in the oven at mixing temperature for 4 hours before compaction. In addition mixtures without curing time were also designed to compare with the mixtures that had been left in the oven for 4 hours. The substitution of natural aggregate for RCA was made in coarse fractions $4 / 8 \mathrm{~mm}$ (only for $30 \%$ of RCA substitution) and 8/16 mm. The aggregate gradation of HMA, an AC 22 base G, for base layers in road pavement construction, was selected according to the Spanish General Technical Specifications for Roads, also known as PG-3 [19]. 


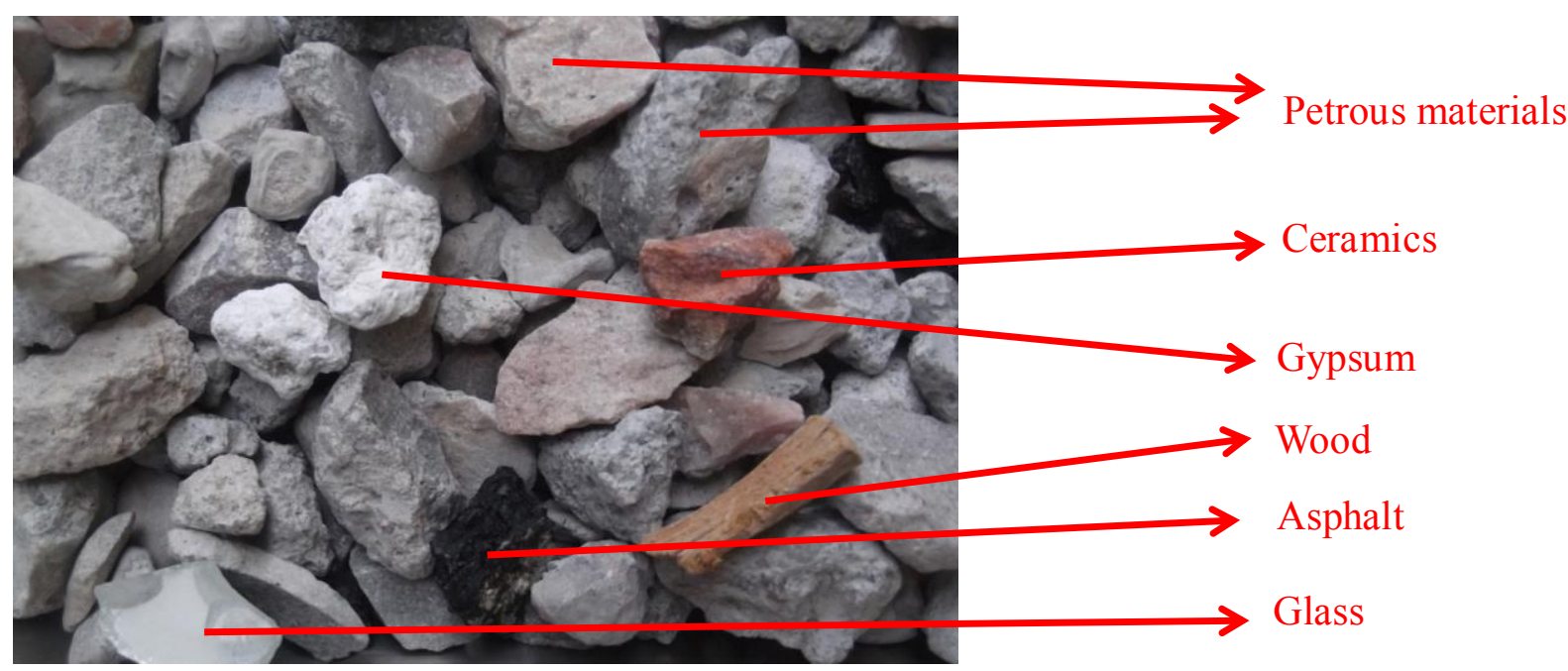

Figure 2: Constituents of RCA used in this investigation.

Water resistance. To evaluate the stripping potential of HMA made with RCA the UNE-EN 12697-12 [20] was followed. In this research, eight sets (HMA cured in the oven for 4 hours and HMA without curing time and percentages of 5\%, 10\%, 20\% and 30\% of RCA ) of ten cylindrical Marshall samples each (compacted with 50 blows per face and manufactured with optimum Marshall bitumen content) were tested. Each set was subdivided into two subsets: the "dry" subset and the "wet" subset. The "dry" subset was kept at room temperature while the "dry" subset was saturated and held in a water bath for 3 days at $40^{\circ} \mathrm{C}$. After this time, the two subsets were left at $15^{\circ} \mathrm{C}$ for a minimum of 2 hours, the "dry" samples in air and the "wet" samples in water. To determine the water resistance of the mixtures, the loss of indirect tensile strength was calculated as follows:

$$
\operatorname{TSR}=\frac{\operatorname{ITS}_{\mathrm{W}}}{\operatorname{ITS}_{\mathrm{D}}} \times 100
$$

where TSR $=$ the tensile strength ratio $(\%), \mathrm{ITS}_{\mathrm{W}}=$ the average tensile strength of "wet" subset $(\mathrm{MPa})$ and $\mathrm{ITS}_{\mathrm{D}}=$ the average tensile strength of "dry" subset (MPa). TSR $\geq 80 \%$ is required by PG3 specifications [19] for HMA for use in base layers.

Stiffness. The indirect tensile stiffness modulus test (ITSM) was used to determine the resilient modulus of HMA Marshall samples (compacted with 75 blows per face at optimum Marshall bitumen content and cured in the oven for 4 hours) in accordance with UNE-EN 12697-26 Annex C [21]. HMA made with 5\%, 10\%, 20\% and 30\% of RCA in place of natural aggregates were tested at the temperature of $20^{\circ} \mathrm{C}$. The resilient modulus was determined following the equation:

$$
\mathrm{M}_{\mathrm{R}}=\frac{\mathrm{F} \times(v+0.27)}{\mathrm{Z} \times \mathrm{h}} .
$$

where $\mathrm{M}_{\mathrm{R}}=$ the resilient modulus $(\mathrm{MPa}), \mathrm{F}=$ the maximum repeated load $(\mathrm{N}), \mathrm{z}=$ the horizontal recoverable deformation $(\mathrm{mm}), \mathrm{h}=$ the thickness of the specimen $(\mathrm{mm})$ and $\mathrm{v}=$ Poisson's ratio (an assumed Poisson's ratio of 0.35 for all of the test temperatures [21] was used). Spanish specifications [19] have no requirements for conventional mixtures in terms of resilient modulus.

Resistance to permanent deformation. To evaluate the resistance to permanent deformation of the mixtures made with RCA and cured for 4 hours in the oven at the optimum Marshall bitumen content, the wheel tracking test following UNE-EN 12697-22:2008+A1 [22] was conducted (figure 
3). In this test two prismatic specimens for each RCA percentage $(5 \%, 10 \%, 20 \%$ and $30 \%)$ were placed inside a climatic chamber at $60^{\circ} \mathrm{C}$ and subjected to the alternating passage of a wheel for 10,000 cycles. The accumulated permanent deformation versus the number of load cycles is measured. The average slope of accumulated permanent deformation between cycles 5,000 and 10,000 is finally determined. According to PG-3 [19] this slope must be lower than $0.07 \mathrm{~mm} / 10^{3}$ cycles.

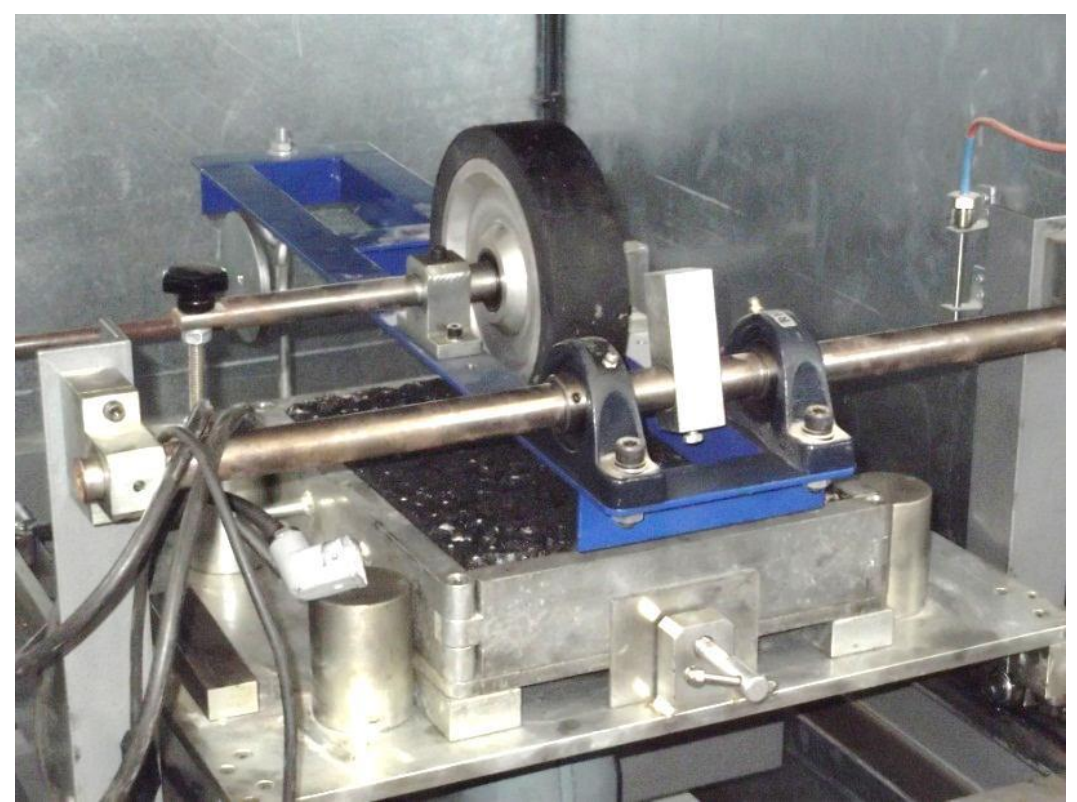

Figure 3: wheel tracking test.

\section{Test results and discussion}

Marshall mix design. Table 1 [23] shows the optimum bitumen content for the HMA made with RCA and cured in the oven for 0 hours and 4 hours. As can be seen, in all cases the bitumen content tends to increase as the RCA percentages increase. Moreover, mixtures manufactured with 4 hours of curing time present greater optimum bitumen content than those made without curing time. It is due to the bitumen absorption onto the pores of the aggregates that takes place during the curing time.

\begin{tabular}{|c|c|c|c|c|c|}
\hline RCA [\%] & $\mathbf{5}$ & $\mathbf{1 0}$ & $\mathbf{2 0}$ & $\mathbf{3 0}$ & $\begin{array}{c}\text { Curing time } \\
\text { [hours] }\end{array}$ \\
\hline Bo [\%] & 3.7 & 3.7 & 3.8 & 4.0 & 0 \\
\hline Bo [\%] & 3.8 & 3.9 & 4.4 & 4.3 & 4 \\
\hline
\end{tabular}

Table 1: optimum Marshall bitumen content of HMA made with RCA that have been left in the oven for 0 hours and 4 hours at mixing temperature before compaction.

Water resistance. Figure 4 shows the tensile strength ratio (TSR) of the mixtures that have been left in the oven for 0 hours and the mixtures that have been left in the oven for 4 hours. As can be seen, HMA that have been cured in the oven for 0 hours don't comply with the Spanish minimum requirement of $80 \%$ of TSR for base layers while the mixtures that have been left in the oven for 4 hours before compaction loosely exceed this value. It demonstrates that the curing time treatment improves the water resistance of the mixtures made with RCA. 


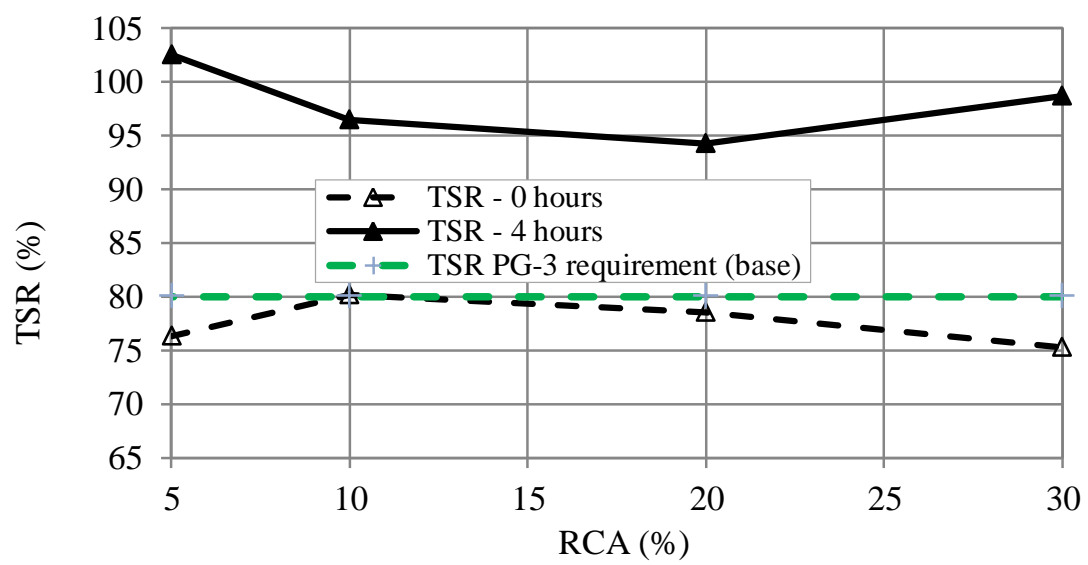

Figure 4: Tensile strength ratio of HMA made with RCA manufactured with 0 hours and 4 hours of curing time.

In addition, as can be seen in figure 5, the indirect tensile strength of the "dry" and the "wet" subset of HMA manufactured with 4 hours of curing time is higher than that of mixtures made without curing time. Moreover, the increase in the TSR value of HMA cured for 4 hours in the oven is due to the greater increase in the indirect tensile strength of the wet subset. That is, the moisture damage performance of HMA cured for 4 hours in the oven improves without being detrimental to their resistance.

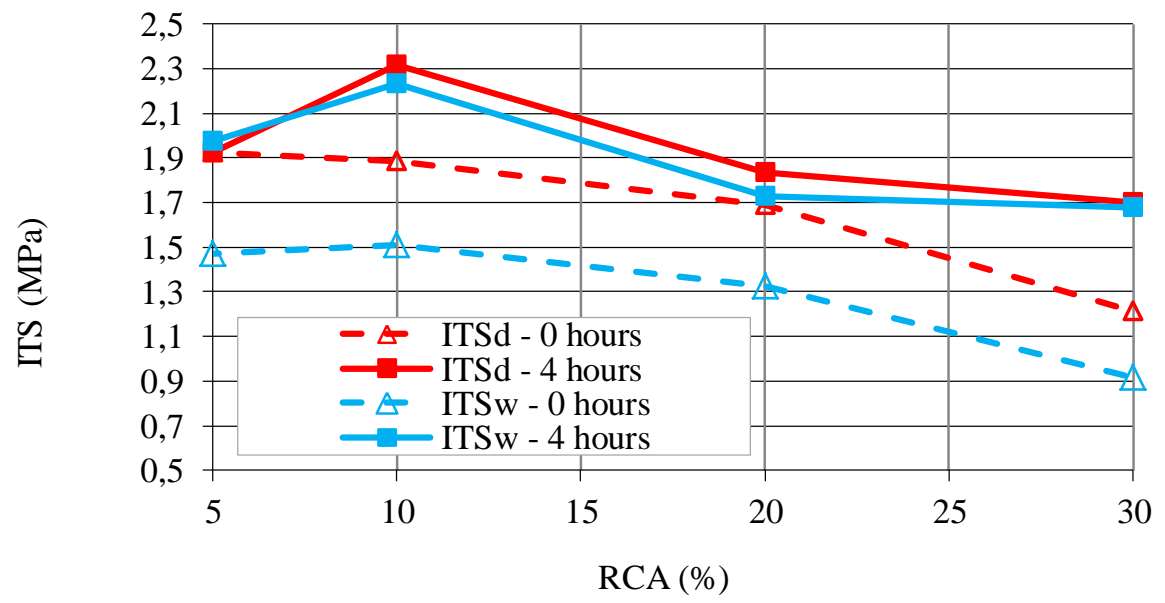

Figure 5: Indirect tensile strength of HMA made with RCA manufactured with 0 hours and 4 hours of curing time.

Stiffness. Table 2 shows the resilient modulus at $20^{\circ} \mathrm{C}$ of HMA made with RCA and cured in the oven for 4 hours. On the one hand, the PG-3 [19] have no specifications for the acceptance of conventional mixtures in terms of resilient modulus, but indicates that for high-modulus mixtures the resilient modulus must be higher than 11,000 MPa. On the other hand, in Spain, an AC 22 base $\mathrm{G}$ as used in this research, has a typical mean resilient modulus of 5,000 $\mathrm{MPa}$ at $20^{\circ} \mathrm{C}$ [24]. As can be seen in table 2, the resilient modulus values of tested HMA are loosely higher than 5,000 MPa and almost reach the minimum value of $11,000 \mathrm{MPa}$. This indicates that the studied mixtures will be stiffer than conventional mixtures and will perform similarly to high-modulus mixtures.

\begin{tabular}{|c|c|c|c|c|}
\hline RCA [\%] & $\mathbf{5}$ & $\mathbf{1 0}$ & $\mathbf{2 0}$ & $\mathbf{3 0}$ \\
\hline $\mathrm{M}_{\mathrm{R}}[\mathrm{MPa}]$ & $9,532.0$ & $10,316.0$ & $10,826.5$ & $10,527.0$ \\
\hline
\end{tabular}

Table 2: resilient modulus at $20^{\circ} \mathrm{C}$ of HMA made with RCA that have been left in the oven 4 hours at mixing temperature before compaction. 
Resistance to permanent deformation. Table 3 shows the average slope of the accumulated permanent deformation at $60^{\circ} \mathrm{C}$ between cycles 5,000 and 10,000 at wheel tracking test of HMA made with RCA cured for 4 hours in the oven. As can be seen, all tested mixtures present an average slope lower than the maximum PG-3 requirement thus, the HMA made with 5\%, 10\%, 20\% and $30 \%$ of RCA and cured for 4 hours in the oven will perform well against rutting.

\begin{tabular}{|c|c|c|c|c|}
\hline RCA [\%] & $\mathbf{5}$ & $\mathbf{1 0}$ & $\mathbf{2 0}$ & $\mathbf{3 0}$ \\
\hline Slope $\left[\mathrm{mm} / 10^{3}\right.$ cycles] & 0.04 & 0.04 & 0.06 & 0.05 \\
\hline PG-3 requirements & \multicolumn{5}{|c|}{$\leq 0.07$} \\
\hline
\end{tabular}

Table 3: average slope of accumulated permanent deformation at $60^{\circ} \mathrm{C}$ between cycles 5,000 and 10,000 at wheel tracking test of HMA made with RCA cured for 4 hours in the oven.

\section{Conclusions}

HMA made with $5 \%, 10 \%, 20 \%$ and $30 \%$ of RCA in place of natural aggregates cured in the oven for 4 hours at mixing temperature have been evaluated. The mixtures were manufactured with Marshall optimum bitumen content. The mixtures displayed a very good water resistance, higher than that of mixtures made without curing time in the oven. In all cases, mixtures that were left in the oven for 4 hours achieved the minimum tensile strength ratio of $80 \%$ required by Spanish specifications. In addition, the improvement of moisture damage performance was achieved without being detrimental for indirect tensile strength resistance. The HMA cured for 4 hours in the oven were stiffer than that made without curing time, with a performance similar to high-modulus mixtures. Moreover, the HMA made with RCA and a curing time of 4 hours presented an adequate resistance to permanent deformation.

\section{Aknowledgements}

The authors wish to acknowledge the Spanish Ministry of Education and Science for sponsoring this research through Project BIA2010-17751.

The authors would like to thank Nynas bitumen for supplying the binder required for this study, TEC-REC for supplying RCA and Cosmos for supplying the Portland cement.

\section{References}

[1]. V.W.Y. Tam, X.F. Gao, C.M. Tam, K.M. Ng, Physio-chemical reactions in recycled aggregate concrete, J Hazard Mater 163.2 (2009), 823-828.

[2]. M. Arm, Self-cementing properties of crushed demolished concrete in unbound layers: results from triaxial tests and field tests, Waste Management 21 (2001) 235-239.

[3]. A. Symonds, Cowi, PRC Bouwcentrum, Construction and Demolition Waste Management Practices, and Their Economic Impacts, Report to DGXI European Commission (1999).

[4]. Y.D. Wong, D.D. Sun, D. Lai, Value-added utilisation of recycled concrete in hot-mix asphalt. Waste Manage 27 (2007) 294-301.

[5]. D. Shen, J. Du, Evaluation of building materials recycling on HMA permanent deformation, Constr Build Mater 18 (2004) 391-397.

[6]. D. Shen, J. Du, Application of Gray Rational Analysis to Evaluate HMA with Reclaimed Building Materials, J Mater Civil Eng 17 (2005) 400-406.

[7]. A.H. Aljassar, K.B. Al-Fadala, Recycling building demolition waste in hot-mix asphalt concrete: a case study in Kuwait, J Mater Cycles Waste 7 (2005) 112-115.

[8]. J. Mills-Beale, Z. You, The mechanical properties of asphalt mixtures with recycled concrete aggregates, Constr Build Mater 24 (2010) 340-345.

[9]. A.K. Mukhopadhyay, B.J. Geiger, J. Button, Use of Alkali-Silica Reaction-Affected Recycled Concrete Aggregate in Hot-Mix Asphalt. Transport Res Rec 2179 (2010) 1-9. 
[10]. S. Bhusal, X. Li, H. Wen, Haifang, Evaluation of Effects of Recycled Concrete Aggregate on Volumentrics of Hot-Mix Asphalt, Transport Res Rec 2205-3 (2011) 36-39.

[11]. M. Chen, J. Lin, S. Wu, Potential of recycled fine aggregates powder as filler in asphalt mixture, Constr Build Mater 25 (2011) 3909 - 3914.

[12]. S. Paranavithana, A. Mohajerani, Effects of recycled concrete aggregates on properties of asphalt concrete, Resour Conserv Recy. No 48 (2006) 1-12.

[13]. I. Pérez, M. Toledano, J. Gallego, J. Taibo, Mechanical properties of hot mix asphalt made with recycled aggregates from reclaimed construction and demolition debris, Mater Construcc 57285 (2007) $17-29$.

[14]. I. Pérez, J. Gallego, M. Toledano, J. Taibo, Asphalt mixtures with construction and demolition debris, Proc Inst Civ Eng. Transp 163 (2010) 165 - 174.

[15]. I. Pérez, A.R. Pasandín, L. Medina, Hot mix asphalt using C\&D waste as coarse aggregates, Mater Design 36 (2012) 840-846.

[16]. I. Pérez, A.R. Pasandín and J. Gallego, Stripping in hot mix asphalt produced by aggregates from construction and demolition waste, Waste Manage Res 30-1 (2012) 3 - 11.

[17]. S. Caro, E. Masad, A. Bhasin, D.N. Little, Moisture susceptibility of asphalt mixtures, Part 1: mechanisms, Int J Pavement Eng 9-2 (2008) 81-88.

[20]. Ministerio de Obras Públicas y Transportes. Normas NLT. Ensayos de carreteras. Dirección General de Carreteras, second edition, Madrid, Spain; 2002.

[19]. MINISTERIO DE FOMENTO. O.C. 24/08 sobre el Pliego de Prescripciones Técnicas Generales para obras de carreteras y puentes (PG-3). Artículo: 542-Mezclas bituminosas en caliente tipo hormigón bituminoso; 2008.

[20]. AENOR. Asociación Española de Normalización y Certificación. UNE-EN 12697-12 "Métodos de ensayo para mezclas bituminosas en caliente. Parte 12: Determinación de la sensibilidad al agua de las probetas de mezcla bituminosa". Madrid, Spain; 2006.

[21]. AENOR. Asociación Española de Normalización y Certificación. UNE-EN 12697-26 "Métodos de ensayo para mezclas bituminosas en caliente. Parte 26: Rigidez". Madrid, Spain; 2006. [22]. AENOR. Asociación Española de Normalización y Certificación. UNE-EN 1269722:2008+A1 "Métodos de ensayo para mezclas bituminosas en caliente. Parte 22: Ensayo de rodadura". Madrid, Spain; 2008.

[23]. Pasandín A.R., Pérez I. "Laboratory evaluation of hot-mix asphalt containing construction and demolition waste ". Constr Build Mater 2013; 43: 497-505.

[24]. Ministerio de Fomento. CEDEX. IECA. Manual de firmes con capas tratadas con cemento. 2003. 